IDENTIFYING THE ROLE OF

AGRICULTURAL EXTENSION SERVICES

IN IMPROVING TECHNICAL EFFICIENCY

IN THE PADDY FARMING SECTOR IN

SRI LANKA
Sri Lanka Journal of

Economic Research Volume 5(1) November 2017

SLJER.05.01.B: pp.63-77

Sri Lanka Forum of University Economists

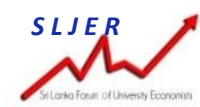

Wasantha Athukorala

\begin{abstract}
The overall aim of this study is to identify the role of agricultural extension services in improving technical efficiency in the rice farming sector in Sri Lanka. Accordingly, the study attempts to investigate how the agricultural extension service received by the farmers can improve technical efficiency (TE), using 200 farm-level data points in Ampara district in Sri Lanka. The Stochastic Production Frontier approach is used to estimate technical efficiency. Results show that the mean TE of rice farming in the study area is 0.61 , although $54 \%$ of rice farmers exceeded this average. This indicates that there is scope to further increase the output by 39 percent without increasing the level of input. It is also found that the contribution of the agricultural officers on increasing technical efficiency level is approximately 13 percent. This implies that production of paddy could be increased significantly by increasing the role of agricultural officers in the country. The overall findings of this research will help implement policies to increase the technical efficiency which is increasingly posing a major impediment to agricultural growth, environmental protection and sustainable development in any country.
\end{abstract}

Key Words: Technical efficiency, Paddy farming, Sri Lanka, Extension services

\title{
Wasantha Athukorala
}

Department of Economics and Statistics, University of Peradeniya, Sri Lanka +94 776862021, athukorala@yahoo.com 


\section{INTRODUCTION}

The rice sector plays an important role in the domestic agricultural sector in the economy. During the period 2005-2015, the annual average contribution of the rice farming sector to the agricultural GDP of the country was approximately 22 percent, while the total contribution from the agricultural sector to national GDP was 15 percent (Central Bank of Sri Lanka, 2015). By 2006, Sri Lanka became 100 percent self-sufficient in rice, which is the staple food of the country ${ }^{1}$. Rice consumption provides about 40 percent of per capita calories and 30 percent of per capita protein of an average Sri Lankan's diet, and accounts for nearly 15 percent of average per capita consumption expenditure (Department of Census and Statistics, 2015). It is believed that rice is the principal contributor to the rural economy in the country, as the majority of rural households engage not only in the production but also the marketing of rice as their main or additional source of livelihood ${ }^{2}$.

The rice sector in Sri Lanka has been facing unprecedented challenges since the early 1960s and early 1970s. During this period, stagnation of yield and production arose as a result of diminishing income following the escalation of costs of production. These issues were mainly due to lack of appropriate policies to improve productivity and efficiency (Karunarathna, 2013; Athukorala and Wilson, 2016). Successive governments in the late 1960s and early 1970s identified the need to increase productivity in the rice farming sector. Data provided by Department of Census and Statistics in Sri Lanka clearly shows that rice production which had been stagnating in the early decades (in 1960s) showed an increasing trend after 1975, with the introduction of modern irrigation technology (e.g. large scale dams, pesticides, fertilisers and new seed varieties). Total paddy production increased drastically from 1975 until the mid-1990s. This is mainly due to an increase in the area under cultivation and also an increase in yield per hectare. The total area under paddy cultivation has increased to 910,491 hectares in 2006 from 457,000 hectares in 1960. Overall, productivity has also increased from $2.16 \mathrm{MT}$ (metric tonnes) per hectare in 1960 to 4.23 MT per hectare in 2010, which is not sufficient in comparison with productivity changes during the same period in other developing and developed countries. For example, paddy productivity in Australia and USA has increased to approximately 8 MT per hectare by 2010 while it has increased significantly in Asian countries such as Vietnam, Philippines, Indonesia and Malaysia.

In Sri Lanka, the relatively high growth rate of the agricultural sector in the past was achieved mainly through the introduction of Green Revolution (GR) varieties and the

\footnotetext{
${ }^{1}$ The self-sufficiency level varies year to year depending on mainly the climatic factor in the country.

${ }^{2}$ There is a possibility of introducing the alternatives cash crops which is beyond the discussion of the scope of this paper.
} 
expansion of cultivated areas. Expansion of cultivated areas was due to large-scale government expenditure on irrigation development and a resettlement program in the dry zone of the country. This pattern of growth can no longer continue since Sri Lanka ran out of new agricultural land over a decade ago (De Silva et al. 1999; Warnakulasooriya and Athukorala, 2016). However, the current policy of the Government of Sri Lanka intends to maintain self-sufficiency in rice production and consumption. These policies should address the need to improve yield by improving productivity and technical efficiency while reducing input usage in the paddy sector. Post-harvest loss as well as soil fertility and salinity issues should also be addressed. One of the way of addressing these issues is to introduce effective agricultural extension services at farm level in order to improve productivity and technical efficiency ${ }^{3}$. It is clear that existing agricultural extension services may not contribute to improving the knowledge of farmers as agricultural extension officers are given specific tasks in the agricultural office besides than providing necessary knowledge to farmers in order to improve yield (Warnakulasooriya and Athukorala, 2016) ${ }^{4}$. Given this background, this study investigates the role of agricultural extension services in improving technical efficiency in the paddy farming sector in Sri Lanka.

The present paper is organised as follows. Section two summarises previous literature in this area while section three outlines the stochastic frontier model and specification of the functional forms. The empirical results are presented in section four and some conclusions are drawn in section five.

\section{LITERATURE REVIEW}

According to Shapiro (1983) the government can enhance productivity among efficient farmers by emphasising on new investment or technologies rather on than extension and education efforts. Tadesse and Krishnamoorthy (1997), Habibullah and Ismail (1994), Obwona (2000) and Karunarathna (2013) have found evidence of technical inefficiency

\footnotetext{
${ }^{3}$ The term efficiency of a farm can be defined as its ability to provide the largest possible quantity of output from a given set of inputs. Technical efficiency measures how well the individual farm transforms inputs into a set of outputs based on a given set of technology and economic factors (Aigner et al., 1977; Kumbhakar and Lovell, 2000). The technical efficiency of an individual firm is defined in terms of the ratio of the observed output to the corresponding frontier output, conditional on the levels of inputs used by that firm (Karunarathna, 2013).

${ }^{4}$ In order to achieve growth in agriculture, either technological innovation or the more efficient use of production technologies, or a balance of both, are required. In developing countries, most new agricultural technologies have only been partially successful in improving productivity. This is often due to a lack of ability or desire to adjust input levels by the producers because of their familiarity with traditional agricultural systems or because of the presence of institutional constraints. These considerations suggest that the best option to assist developing countries to increase yield is increasing efficiency (Karunarathna, 2013).
} 
among farmers in developing countries. They showed the importance of using education, agricultural extension, social change and support as the main strategies to improve efficiency levels in agriculture. Parikh and Shah (1995) measured technical efficiency in Pakistan using cross-sectional data from 397 farms during the 1988/89 cropping season and found that the average technical efficiency level was $96.2 \%$. The results of the study shows that the estimated farm-level technical efficiency depends on levels of credit and education, farmers' ages, and the extent of land fragmentation. Owens et al. (2001) investigated the impact of farmer contact with agricultural extension services on farm productivity using panel data obtained during the 1993-1997 period in Zimbabwe. The results showed that access to agricultural extension services raises the value of crop production by about $15 \%$. The results also show that the impact of agricultural extension services differed across individual crop years, with the impact being markedly different in drought and non-drought years.

Abdulai and Huffman (2000) have shown the lower level of technical efficiency measures for Ghana's agriculture. They found that average efficiency for rice farmers in Northern Ghana is $63 \%$, with profit efficiency ranging between $16 \%$ and $96 \%$. According to them about $27 \%$ of potential maximum profit is lost to inefficiency. Seidu (2004) provided evidence to show that smallholder rice farmers in the Upper East region of Ghana produce, on average, 34\% below maximum output. They found that the estimated technical efficiency for smallholder irrigators and non-irrigators as $48 \%$ and $45 \%$ respectively, while that of male farmers stood at 58\% compared with $34 \%$ for female farmers. Rahman and Hasan (2008) similarly concluded that providing an agricultural information source could increase the technical efficiency of farmers in Bangladesh. Rahman and Rahman (2008) suggest that increase of extension services and the application of technology could increase the technical efficiency of farmers and thus increase rice production in Bangladesh. Jahan and Pemsl (2011) found that training had significant positive effects on the technical efficiency of farmers, total farmer productivity, and the net income of small-scale farmers in Bangladesh. Bello et al. (2012) attempted to identify factors affecting the use of rice farming technology in Central Nigeria. Accordingly the characteristics of farmers such as age, size of household, social participation, agricultural experience, land area, income of farms and extension contacts, explained $67.0 \%$ of the variation in the application of rice technology by farmers. However, it was found that income was not related to the level of technical efficiency for rice farms.

Wakili and Md Isa (2015) investigated the technical efficiency of rice production in Adamawa State in Nigeria using sample data taken from 150 irrigated rice farmers and 225 rainfed rice farmers. This study used stochastic frontier model to analyse the technical efficiency of the rice farmers in both systems. According to the results the estimated elasticity of rice output with respect to farm size, seed and fertiliser were statistically 
significant in both systems. It is also found that the mean technical efficiency of the irrigated rice farmers was $76 \%$, while rainfed rice farmers have a mean technical efficiency of $71 \%$. Rasyid et al. (2016) estimates the effect of production input on rice production and the effect of socioeconomic factors on the technical efficiency of rice farms using data collected from 78 rice farmer household heads from two randomly chosen villages in Indonesia. The results show that seed, fertiliser, pesticides and labour significantly positively affect rice production. Socioeconomic factors such as farmer age, education and experience, the number of household members and the frequency of visiting the Integrated Crop Management Field School field laboratory had significant positive effects on the level of technical efficiency.

A few studies in Sri Lanka address the technical efficiency in rice farming sector. Gedara et al. (2012) examine the factors affecting the technical efficiency (TE) of irrigated rice farmers in village irrigation systems (VIS) in Sri Lanka. Accordingly, the mean TE of rice farming in village irrigation was found to be 0.72 , although $63 \%$ of rice farmers exceeded this average. The most influential factors of TE are membership in Farmer Organisations (FOs) and participation in collective actions organised by FOs. Aruna Shantha et al. (2013) investigates the technical efficiency of rice farming in major irrigation schemes in Sri Lanka. The results obtained from the stochastic frontier estimation in this study found that the average technical efficiency of selected farmers is 72.80 percent. This indicates that there is scope to further increase the output by 27.2 percent without increasing the level of input. Warnakulasooriya and Athukorala (2016) evaluate technical and allocative efficiencies of rice farming in the low country rainfed water regime of the Gampaha and Kalutara districts of Sri Lanka. They found that the increase of technical efficiency has resulted in potential cost savings of approximately 33 per cent in Gampaha and 27 per cent in Kalutara district in the Yala season, and 24 per cent in Gampaha and 22 per cent for Kalutara in the Maha season. In general, it becomes clear that none of these studies considered the role of agricultural extension services on the TE in rice farming which will be the main focus of this study.

Technical efficiency is an important factor in productivity growth in agriculture. When the existing resources are scarce and the opportunities for developing new technologies are lacking, improving efficiency without increasing the resource base or developing new technology is the main strategy of increasing production. In this context, it is clear that a large number of studies have attempted to investigate technical efficiency in rural agriculture. However, only few studies have concentrated on understanding the role of agricultural extension services in improving technical efficiency in the paddy farming sector. Further, no study attempts to investigate the role of agricultural extension services on TE in the Sri Lankan context. This study attempts to fill this void in the literature. 


\section{EMPIRICAL ESTIMATION METHOD}

A stochastic frontier production function comprises a production function of the usual regression type with a composite disturbance term equal to the sum of two error components. (Meeusen and Van de Broeck, 1977). One error component represents the effect of statistical noise while other error component captures systematic influences that are unexplained by the production function and are attributed to the effect of technical inefficiency. The approach of the frontier production function used in this study is based on a model developed by Coelli et al. (2005), which follows the form of the Cobb-Douglas model:

$\ln Y_{i}=\beta_{0}+\sum_{j=1}^{5} \beta_{j} \ln X_{i j}+V_{i}-U$

Where,

In represent the natural logarithm

The subscript $i$ indicates the $i^{\text {th }}$ farmer in the sample $(i=1,2, \ldots \ldots . .200)$

$\mathrm{Y}_{\mathrm{i}}$ represents the paddy output-Kg (FOUT)

$\mathrm{X}_{1}$ represents the total area of land under cultivation (in acres) (LAN)

$\mathrm{X}_{2}$ represents the labour in man-days (LAB)

$\mathrm{X}_{3}$ represents the capital expenditure - machinery expenditure $(\mathrm{K})$

$\mathrm{X}_{4}$ represents the expenditure for pesticides and fertilisers (FER)

$\beta_{\mathrm{j}}$ 's are unknown parameters to be estimated

$\beta_{0}$ is constant

$\mathrm{V}_{\mathrm{i}}$-random errors and $U_{i}$-non-negative random variables (technical inefficiency)

In the first phase of analysis, technical efficiency effects for a cross section of farmers were modelled in terms of input variables in the production process. Total paddy output in terms of kilograms was the dependent variable. Inputs were categorised into four groups: land, labour, capital (machinery) and agro- chemical inputs (pesticides and fertilisers). After estimating the production function, the technical efficiency of the farmer and the $\mathrm{i}^{\text {th }}$ farm production was estimated as follows (Coelli et al. 2005):

$$
T E_{i}=\frac{Y_{i}}{Y_{i}{ }^{*}}=\frac{\exp \left(X_{i} \beta+V_{i}-U_{i}\right)}{\exp \left(X_{i} \beta+V_{i}\right)}
$$

where, $\mathrm{Y}_{\mathrm{i}}$ is the observed production and $\mathrm{Y}_{\mathrm{i}}^{*}$ is the expected frontier production based on the stochastic frontier production function.

After estimating technical efficiency, technical inefficiencies in each farm can be predicted. A multiple linear regression model was then used to identify the impacts of socio-economic variables on technical inefficiency. 
The empirical model is as follows:

$$
U_{i}=\alpha_{0}+\alpha_{1} Z_{1 i}+\alpha_{2} Z_{2 i}+\alpha_{3} Z_{3 i}+\alpha_{4} Z_{4 i}+\alpha_{5} Z_{5 i}+\alpha_{6} Z_{6 i}+\alpha_{7} Z_{7 i}+\alpha_{8} Z_{8 i} g_{i} \ldots \text { (3) }
$$

where $\alpha_{0}$ is constant

$$
\begin{aligned}
& Z_{1 t} \text { is the age of the farmer (AGE) } \\
& Z_{3 t} \text { is the household size (HS) } \\
& Z_{4 t} \text { is the labour composition-ratio of hired labour to total labour used (RFH) } \\
& Z_{5 t} \text { is the land ownership (LO) } \\
& Z_{7 t} \text { is farm visit by agricultural officers or extension officers (FV) } \\
& Z_{8 t} \text { the number of direct contacts of the agricultural extension officers (NAE) }
\end{aligned}
$$

The first three variables included into the inefficiency model are assumed to be directly related to farmers' management skills, while the latter could impact their technical efficiency through the availability of labour and man power for the timely management of farming activities or incentives for increasing efficiency in farms. Older farmers are expected to be associated with higher levels of inefficiency, partly because older farmers tend to be less adaptable to technical developments.

\section{Table 1: Variables and Their Definitions}

\begin{tabular}{ll}
\hline Variable & Definitions \\
\hline AGE & Age of the respondent (number of years) \\
EDU & Formal education level of the respondent(number of years) \\
HS & Household size( number of the members whose age is greater than 14) \\
RFH & Labour composition-ratio of hired labour to total labour used \\
LO & Land ownership: dummy variable- If owned 1, otherwise 0 \\
OFI & Off farm income: monthly income from other activities (Rs.) \\
FV & Farm visit by agricultural officers or extension officers: dummy variable- If \\
& visited 1, otherwise 0 \\
NAE & Number of direct contacts of the agricultural extension officers during the \\
& season
\end{tabular}

Note: There are 3 main agriculture related government officers in Grama Nilladary(GN) or Divisional Secretariat (DS) level in Sri Lanka. While their role and tasks are different, most farmers take their advices in various ways for the cultivation.

The expected sign of the labour composition-ratio of hired labour to total labour can be negative or positive depending on whether hired labour is more efficient or not. Land ownership could result in different empirical results. It is hypothesised that an increased number of agricultural extension contacts as well as farm visits by agricultural officers or extension officers, ceteris paribus, are expected to reduce technical inefficiency. The 
model for the technical inefficiency effects specifies that technical inefficiency is a function of a number of variables which are explained in Table 1.

Given the functional and distributional assumptions, maximum-likelihood estimates (MLE) for all parameters of the stochastic frontier production and inefficiency models defined in Equations 1 and 2 will be simultaneously estimated using the program FRONTIER 4.1 (Coelli, 1996). The TE of a farmer is between 0 and 1 and is inversely related to the level of the technical inefficiency effects (Battese and Coelli, 1995). In this study various tests were conducted at the beginning of the empirical estimation. Frontier 4.1 allows various choices in relation to the model's functional form and inefficiency distribution. First, hypothesis tests based on the generalised Likelihood Ratio (LR) test was conducted to select the functional form. Second, the distributional assumptions were tested based on the likelihood ratio test statistic and the truncated-normal assumption was strongly accepted. Third, the truncated-normal Cobb-Douglas specification was tested for the existence of a frontier. As the truncated-normal Cobb-Douglas specification was accepted, models were estimated.

Data for this study was collected from a survey conducted covering 10 villages (these 10 villages were selected purposively) in Ampara districts. The study is based on crosssectional data collected during the 2016 agricultural production year in the area. A combination of purposive and random sampling was used in the survey. The choice of the study area was purposive because of the concentration of rice farmers in the area, while the selection of the rice growers in the sample was random. First we obtained the list of rice growers in those villages and then having assigned a number for each, randomly selected the sample. A structured questionnaire was used to collect relevant information from 200 randomly selected rice farmers about their socio-economic characteristics, inputs such as area cultivated, value of fertilizer and labour used, and outputs such as the value of paddy harvested. The survey was conducted by six highly trained undergraduates over a period of approximately two months. A well-structured and field pre-tested comprehensive interviewing schedule was used for the collection of detailed information on various aspects of paddy farming in the area.

\section{RESULTS AND DISCUSSION}

The summary of the sample statistics of the respondents are presented in Table 2. The average age of the farmer was 48 years, indicating that a majority of old people are involved in farming activities. Rice farming in the study area is dominated by male farmers, a majority of whom are married. 
Table 2: Summary of Descriptive Statistics

\begin{tabular}{lrrrr}
\hline \multicolumn{1}{c}{ Variable } & Mean & Maximum & Minimum \\
\hline Output(Kg/ per acre) & & 2100 & 2875 & 1150 \\
Land (acres) & 1.25 & 3.25 & 0.25 \\
Capital expenditure (Rs.) & 15400 & 28600 & 8500 \\
Labour days(No.) & 42 & 61 & 22 \\
Fertilizers quantity (Kg.) & Urea & 96 & 115 & 55 \\
& TSP & 28 & 32 & 12 \\
& MOP & 26 & 30 & 18 \\
Age(years) & & 48 & 67 & 24 \\
Education (year) & & 9 & 14 & 6 \\
Household size (No.) & & 4 & 6 & 2 \\
Off farm income (Rs.) & & 4 & 6 & 2500 \\
Contacts with agricultural & extension officers & & & 0 \\
(No.) & & & & \\
\hline
\end{tabular}

Note: Average per acre is recorded in the table except the land variable TSP-Triple Super phosphate, MOP- Muriate of Potash

The average fertiliser quantity used is $150 \mathrm{~kg}$ per acre which is higher than recommended. It is also observed that the proper recommended combination of fertilisers is not being used by farmers. On average, farmers in the study area have a good education level of nine years, and farming experience of 12 years on average. Most farmers cultivate about 1.25 acres of land which shows farming in the study area operates on a small scale.

The average rice yield is $2,100 \mathrm{~kg}$ per acre which is slightly higher than the national average in district. However, a higher variation in yield could be observed among different farms. High variation in yield could be due to difference in different paddy varieties, planting time, soil quality, different levels of input use and random shocks. A huge gap of $1,725 \mathrm{~kg}$ between maximum and minimum yield per acre suggests that there are constraints on the farmer's side which create hurdles to increasing rice yield from a given set of technology and resources. Given this socioeconomic background, as the first step the Cobb-Douglas production function was estimated. In this case, output elasticities with respect to the inputs $\mathrm{X}_{\mathrm{i}}$, for the Cobb-Douglas were obtained by mean differencing all the variables before estimation (Coelli et al. 1998). With this, the elasticities for the four inputs were the coefficients of the direct Cobb-Douglas production function and the returns to scale coefficient, $\epsilon$, was the sum of the elasticities of the inputs. The estimated parameters of the stochastic frontier production function for the paddy farming in the study area is presented in Table 3 . 
Table 3: Maximum Likelihood Estimates of the Cobb Douglas Stochastic Frontier Function

\begin{tabular}{lrr}
\hline \multicolumn{1}{c}{ Variable } & Coefficient & \multicolumn{1}{c}{ t value } \\
\hline Intercept & 15.361 & $5.432 * * *$ \\
LAN & 0.232 & $2.961 * * *$ \\
LAB & 0.431 & $3.211^{* * *}$ \\
K & 0.115 & $2.481 * *$ \\
FER & 0.173 & $3.121 * * *$ \\
Sigma-squared & 0.575 & $8.339 * * *$ \\
Gamma & 0.612 & $12.452 * * *$ \\
Log Likelihood Ratio & -152.96 & \\
\hline
\end{tabular}

Note: *** Significant at $1 \%$ level $* *$ significant at $5 \%$ level.

The result indicates that all variables in the production function are positive: indicating that as the variable of input increases, output also increases. All variables except capital expenditure which mainly includes machinery power are significant at one percent level of significance while capital expenditure is significant at five percent. Among input variables, the role of labour in paddy production is relatively higher as its coefficient value is 0.431 . The return to scale value of 0.951 was obtained from the summation of the coefficients of the estimated parameters, which indicates decreasing returns to scale. It also implies that all inputs were used within the rational stage of production function and that there is no potential to increase output by changing the scale of production in the study area. The variance ratio (gamma) is estimated to be $61.2 \%$, meaning that about $61 \%$ of the discrepancies between observed output and the frontier output are due to technical inefficiency. In other words, the shortfall of observed output from the frontier output is primarily due to factors, which are within the control of the paddy farmers in the study area. Prediction of technical efficiency level revealed that the mean TE of rice farming in the study area was 0.61 , although $54 \%$ of rice farmers exceeded this average.

As the second step of analysis, inefficiency models were estimated. First, the model was estimated including only two variables (FV, NEF) which capture the impacts of agricultural officers' role on changing the inefficiency in the paddy farming. Results show that these two variables are highly significant and both could be used to reduce the technical inefficiency as policy variables in the country. Then the complete model including all variables was estimated. The results of the inefficiency models are reported in Table 4. 
Table 4: Parameter Estimation for Technical Inefficiency Level of Paddy Farmers

\begin{tabular}{lccrr}
\hline \multicolumn{1}{c}{ Variable } & \multicolumn{2}{c}{ Model 1 } & \multicolumn{2}{c}{ Model 2 } \\
& Coefficients & $\mathrm{t}$ value & Coefficients & \multicolumn{1}{c}{ t value } \\
\hline Intercept & 4.681 & $5.213^{* *}$ & 2.312 & $3.461^{* * *}$ \\
AGE & & & 0.014 & $1.622^{* *}$ \\
EDU & & & -0.028 & $2.815^{* * *}$ \\
HS & & & -0.018 & $1.561 * *$ \\
LR & & & 0.001 & 1.234 \\
LO & & & -0.004 & $2.912^{* * *}$ \\
OFI & & & -0.125 & $3.127 * * *$ \\
FV & -0.082 & $4.321 * * *$ & -0.008 & $3.174 * * *$ \\
NAE & -0.127 & $3.785^{* * *}$ & -0.042 & $2.982 * * *$ \\
\hline $\mathrm{N}$ & 200 & & 200 & \\
$\mathrm{R}^{2}$ & 0.293 & & 0.628 & \\
\hline
\end{tabular}

Note: i. *** Significant at $1 \%$ level $* *$ significant at $5 \%$ level.

ii. We have estimated the specific model(after controlling the variables-controlled model) and the general model(uncontrolled model) in order to investigate the impact of the interested variables in the model.

iii. Results of the general model is used for interpretation

The result of the inefficiency effects of the stochastic frontier production shows that all the variables except RFH of the inefficiency effects are significant either $1 \%$ or $5 \%$ level of significance and they have shown the expected sign.

The age of paddy farmers had a positive effect on the level of technical inefficiency. This indicates that younger farmers are more efficient than relatively older farmers. As age of farmers are positively correlated with paddy farmers' experience, we did not include experience variable in the model. The coefficient of education is significant and has taken the expected sign. In general, education is very important in improving the efficiency of the farmers in the study area, because the farmers can take the correct decisions on using inputs if they are educated.

The results show that education can significantly reduce inefficiency in farming. The coefficient of household size is also significant in indicating that large families can use more labour for their farming which can reduce technical inefficiency. Labour ratio (LR) variable is not significant. This mean that whether farmers use family labour or hired labour is not important in determining the efficiency level of their farms. Land ownership (LO) and off-farm income (OFI) variables are significant at one percent level. This shows that the higher the ownership as well as the off-farm income of farmers, the better their ability to apply technology and resources to increase the efficiency level of the farms. Finally, the results of the study show that the agricultural officers' visits to farms as well 
as farmers meeting agricultural extension officers for advice could increase farm level technical efficiency.

As the final step of this analysis, distribution of technical efficiency scores are investigated. Frequency distribution of technical efficiency for individual farms is given in Table 5.

\section{Table 5: Frequency Distribution of Technical Efficiency for Individual Farms}

\begin{tabular}{lrr}
\hline \multicolumn{1}{c}{ Efficiency Level } & Frequency & \multicolumn{2}{c}{ Percentage } \\
\hline $0.00-0.10$ & 0 & 0.0 \\
$0.11-0.20$ & 3 & 1.5 \\
$0.21-0.30$ & 10 & 5.0 \\
$0.31-0.40$ & 15 & 7.5 \\
$0.41-0.50$ & 22 & 11.0 \\
$0.51-0.60$ & 53 & 26.5 \\
$061-0.70$ & 45 & 22.5 \\
$0.71-0.80$ & 22 & 11.0 \\
$0.81-0.90$ & 17 & 8.5 \\
$0.91-1.00$ & 13 & 6.5 \\
\hline
\end{tabular}

Note: total number of farmers is 200 .

It is evident that there is great variation in the levels of efficiency - the range is from $16.2 \%$ to $96.8 \%$ with a mean of $80.6 \%$. The mean level of technical efficiency in the study area is $62.1 \%$. Results shows that approximately $25 \%$ of the farmers have a technical efficiency level below 0.5 and that around $49 \%$ of farmers belonged to the 0.5 to 0.7 efficiency range. Further, $6.5 \%$ of the farmers belong to the most efficient category ( 0.9 to 1.00 ) while $1.5 \%$ belonged to the least efficient category (less than 0.2 ). In general, the distribution of efficiency scores indicates that most paddy farmers are inefficient and that there is room for improvement in the efficiency of farmers in the study area.

\section{CONCLUSION AND POLICY IMPLICATIONS}

This study attempts to identify the role of agricultural extension services in improving productivity and technical efficiency in paddy farming sector in Sri Lanka. Farm household data covering 200 households from Ampara district were used for the main analysis. The results show that paddy production in the study area can be increased by approximately 39 per cent with the current levels of inputs and technology if less efficient farms are encouraged to follow the resource utilisation pattern of the most efficient farmers. It is found that the inefficiency level is negatively and significantly correlated with the age, education level, household size, land ownership, off farm income, visits to the paddy farm by agricultural officers and contact with agricultural extension officers. 
In general the estimated coefficients for the inefficiency function provide some explanation for the relative efficiency levels among the paddy farmers in the study area. Therefore, policies should target improving the educational status of paddy farmers and increasing the role of agricultural officers in improving farm production in rural paddy farming areas in Sri Lanka. Improving farmers' efficiency will increase their income and food security while reducing rural poverty in Sri Lanka.

\section{REFERENCES}

Abdulai, A., \& W. Huffman. (2000). Structural Adjustment and Economic Efficiency of Rice Farmers in Northern Ghana. Economic Development and Cultural Change, 48(3), 503-20.

Aruna Shantha, A., Asan Ali, B. G. H., Bandara. R. A. G. (2013). Technical Efficiency of Paddy Farming Under Major Irrigation Conditions in the Dry-Zone of Sri Lanka: A Parametric Approach. Australian Journal of Basic and Applied Sciences, 7(6), 104-112.

Athukorala, W., \& Wilson, C. (2016). Distributional Impacts of Irrigation Induced Agricultural Development in a Semi-subsistence Economy: New Evidence. Environmental Economics and Policy Studies, 19(1), 59-75.

Battese, G. E., \& Coelli, T. J. (1988). Prediction of Firm-level Technical Efficiencies with a Generalised Frontier Production Function and Panel Data. Journal of Econometrics, 38(3), 387-399.

Battese, G. E., \& Coelli, T. J. (1995). A Model for Technical Inefficiency Effects in a Stochastic Frontier Production Function for Panel Data. Empirical Economics, 20(2), 325332.

Bello, M., Salau, E.S. \& Ezra, L. (2012). Analysis of Factors Influencing Discontinuance of Technology Adoption: The Situation with Some Nigerian Farmers. Sustainable Agric. Res., 1, 292-300.

Central Bank of Sri Lanka. (2017). Annual Report- 2013. Colombo: Central Bank of Sri Lanka.

Coelli, T. J. (1996). A Guide to Frontier version 4.1: A Computer Program for Stochastic Frontier Production and Cost Function Estimation, CEPA Working Papers No. 7/96, Department of Econometrics University of New England: Armidale.

Coelli, T. J. (1996). Recent Developments in Frontier Estimation and Efficiency Measurements. Australia Journal of Agricultural Economics, 39(3), 219-245.

Coelli, T. J., Rao, D. S. P., Donnell, C. J. O., \& Battese, G. E. (2005). An Introduction to Efficiency and Productivity Analysis. New York: Springer. 
Department of Census and Statistics. (2012). Household Income and Expenditure Survey 2007. Department of Census and Statistics: Colombo.

Habibullah, M.S., \& Ismail, M.M. (1994). Production Frontier and Technical Efficiency: The Case for Beekeeping Farms in Malaysia. Bangladesh Journal of Agricultural Economics 17 (1\&2), 31-43.

Hoang, V., \& Coelli, T. (2009). Measurement of Agricultural Total Factor Productivity Growth in Corporating Environmental Factors: a Nutrients Balance Approach. Working Paper, Centre for Efficiency \& Productivity Analysis, University of Queensland, Australia.

Jahan, K.M.E., \&. Pemsl, D.E. (2011). The Impact of Integrated Aquaculture-Agriculture on Small-scale Farm Sustainability and Farmers' Livelihoods: Experience from Bangladesh. Agricultural System, 104, 392-402.

Gedara,K. M., Wilson, C., Pascoe, S., \& Robinson, T. (2012). Factors Affecting Technical Efficiency of Rice Farmers in Village Reservoir Irrigation Systems of Sri Lanka. Journal of Agricultural Economics, 63(3), 627-638.

Gunaratne, R. U. M. S., \& Thiruchelvam, S. (2002). Comparative Study on Technical Efficiency of Paddy Production Under Major and Minor Irrigation Schemes in Anuradhapura district. Tropical Agricultural Research, 14.

Karunarathna, K. M. R. (2013). Agricultural Biodiversity, Farm Level Technical Efficiency and Conservation Benefits: An Empirical Investigation, (Doctoral dissertation), Queensland University of Technology.

Obwona, M. (2000). Determinants of Technical Efficiency Differentials amongst Small and Medium Scale Farmers in Uganda: A Case of Tobacco Growers. A Final Report Presented at AERC bi-annual Workshop at Grand Requency Hotel, Nairobi, Kenya.

Owens, T., Hoddinott, J., \& Kinsey, B. (2001). The Impact of Agricultural Extension on Farm Production in Resettlement Areas of Zimbabwe. Working Paper Series 2001-6. Centre for the Study of African Economies, University of Oxford.

Parikh, A., \& Shah, K. (1995). Measurement of Technical Efficiency in the North-West Frontier province of Pakistan. Journal of Agricultural Economics, 45, 133-37.

Rahman, S., \& Hasan M. K. (2008). Impact of Environmental Production Conditions on Productivity and efficiency: A case study of wheat farmers in Bangladesh. J. Environ. Manage, $88,1495-1504$.

Rahman, S., \& Rahman, M. (2008). Impact of Land Fragmentation and Resource Ownership on Productivity and Efficiency: The Case of Rice Producers in Bangladesh. Land Use Policy, 26, 95-103. 
Rasyid M. N., Setiawan, B., Mustadjab, M. M., \& Hanani. N. (2016). Factors that Influence Rice Production and Technical Efficiency in the Context of an Integrated Crop Management Field School Program. American Journal of Applied Sciences 13 (11), 1201-1204.

Seidu, A., Sarpong, D. A., \& Al-hassan, R. (2004). Allocative Efficiency, Employment and Rice Production Risk: An Analysis of Smallholder Paddy Farms in the Upper East Region of Ghana. Faculty of Integrated Development Studies, University for Development Studies. Journal of Development Studies, 1(2): 142-63.

Shantha, A., Ali, A. B.G.H., \& Bandara, R. A. G. (2013). Technical Efficiency of Paddy Farming Under Major Irrigation Conditions in the Dry-Zone of Sri Lanka: A Parametric approach, Australian Journal of Basic and Applied Sciences, 7(6), 104-112.

Shapiro, K. H. (1983). Efficiency Differentials in Peasant Agriculture and their Implications for Development Policies. Journal of Development Studies, 19(2), 177-190.

Tadesse, B, \& Krishnamoorthy, S. (1997). Technical Efficiency in Paddy Farms of Tamil Nadu: An Analysis based on Farm Size and Ecological Zone. Journal of Agricultural Economics, 16, 185-192.

Wakili, A. M., \& Md Isa. A. H. (2015). Technical Efficiency of Small Scale Rice Production in Adamawa State, Nigeria. International Conference on Chemical, Food and Environment Engineering (ICCFEE-15), Dubai (UAE).

Warnakulasooriya, H. U., \& Athukorala, W. (2016). Productive Efficiency of Rice Farming under Rainfed Conditions in the Gampaha and Kalutara districts of Sri Lanka. Sri Lanka Journal of Food and Agriculture, 2(1), 51-64. 
